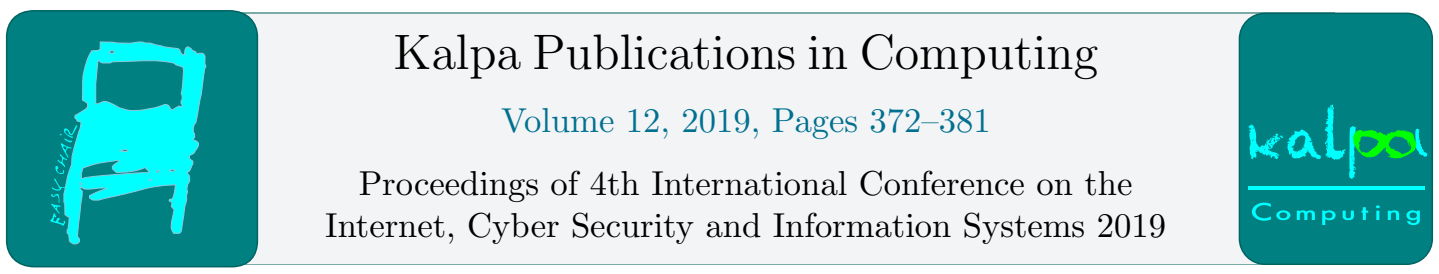

\title{
Strategic Cloud Computing Framework: A South African Context
}

\author{
Andrian Wilby Twala ${ }^{1}$ and Ray Kekwaletswe ${ }^{2}$ \\ ${ }^{1}$ Graduate School of Business Leadership, University of South Africa, Midrand, South Africa \\ Twalaawetut.ac.za \\ ${ }^{2}$ School of Economic and Business Sciences, University of the Witwatersrand, Johannesburg, \\ South Africa. \\ RayKekwaletswe@gmail.com
}

\begin{abstract}
Cloud computing is internet-based computing in which users can share information technology resources in a secure and efficient system [1]. South African organisations by adopting and using technology such as cloud computing can leverage on its ability to offer a flexible resource that is scalable to the needs of an organization, which are accessible from anywhere at any time. The main goal of this study was to conceptualise a strategic cloud computing framework in the context of South African information technology professions. This study used stakeholder theory, contingency theory, and technology-organization-environment theory as research lenses. The study used interpretivism research philosophy. The primary data was collected using semi-structured interviews from 21 individual IT professionals. The key findings are that IT professionals recognized the importance and benefits of cloud computing. In addition, stakeholders have an influence on cloud computing use and adoption. The IT strategy needs to be aligned with the business strategy for cloud computing to be smoothly adopted and use in an organisation. The study concluded that there is a need for a strategic cloud computing framework that would help to strategically adopt and use cloud computing in a uniformed and coordinated manner in South African organisations.
\end{abstract}

\section{Introduction}

In today's world, companies are finding new ways to improve access to their product offering, to operate efficiently, to cut costs by leveraging on information technology. In the last decade, these been an increase in the use of technology such as cloud computing. Cloud computing is defined as the delivery of information technology (IT) resources via the internet [2].

According to a review of [3], cloud computing has the potential to change the wat IT resources are consumed. A review of literature by [4], [5] concurs that cloud computing has benefits such as pay as 
you use model, scalability, flexibility, reliable service, improved efficiency and cost-saving. Cloud computing can be leveraged by South African companies since it offers flexible and scalable resources, pay as you use model, access to resources from anywhere at any time and fast deployment of technology [6].

This paper uses the theories of stakeholder theory, contingency theory and technology-organizationenvironment theory to understand how cloud computing could be strategically adopted and used in the context of the South African IT professionals. The paper develops a strategic cloud computing framework in the context of South African IT professional's views, experiences and opinions about the adoption and use of cloud computing.

The objectives of the study are to:

- Analyse the landscape of cloud computing through the eyes of IT professionals.

- Analyse the drivers of cloud computing for different stakeholders.

- Analyse and describe practical and theoretical contingencies for cloud computing.

- Analyse and describe factors influencing cloud computing amongst South African information technology professional

The rest of the paper is organized as follows. The next section will discuss the theoretical frameworks that are underpinning this study. Research methods are discussed in section 3. Key findings are discussed in section 4. A conclusion is discussed in section 5 .

\section{Theoretical Background}

In this section, the theoretical frameworks are discussed. This study is underpinned by the theories of Stakeholder theory by [7], Technology-Organization-Environment by [8], and Contingency theory by [9]. The theories are discussed below.

\subsection{Stakeholder Theory}

The stakeholder theory was first introduced by [7] in 1984. The stakeholder theory was used to understand the relationship between management and stakeholders. Freeman defined stakeholders as "any group or individual that can affect or is affected by the achievements of the organisation's objectives."

The stakeholder theory describes the value that is being created when stakeholders are working together. The theory originally presented the stakeholder model as a map in which organisation is the hub of a wheel and stakeholders are at the end of spokes around the rim. The stakeholder map is shown in figure 1. 


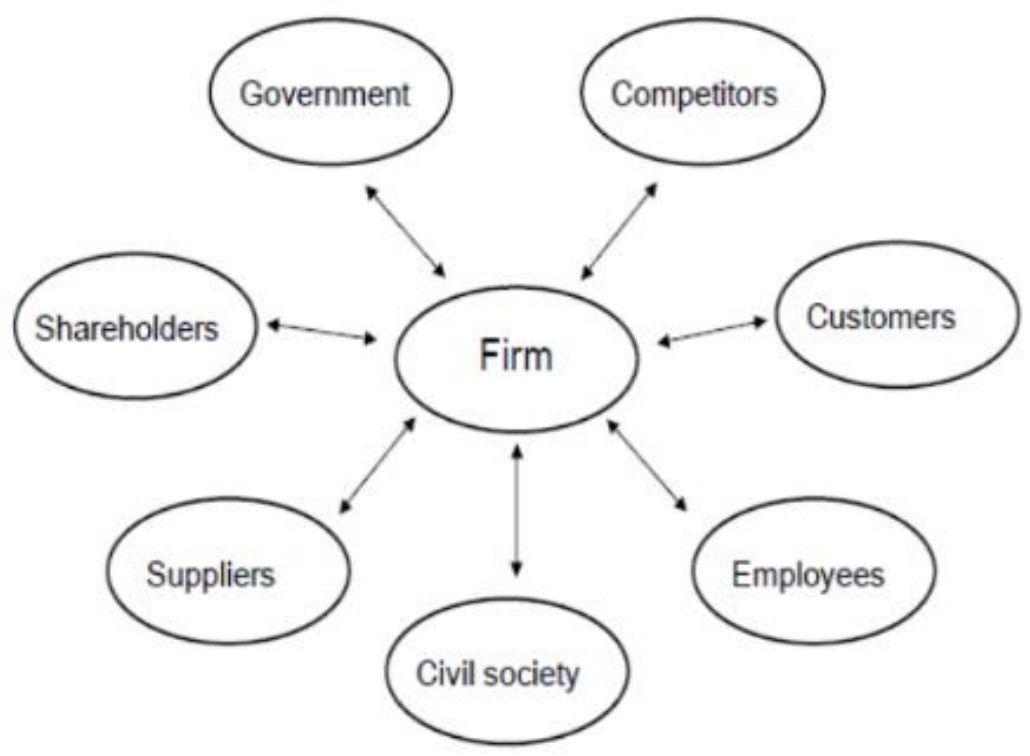

Figure 1: Stakeholder model (Freeman, 1984)

\subsection{Technology-Organization-Environment}

Technology-organization-environment (TOE) framework was developed by [8] in 1990. The TOE examines the process of how an organization goes about adopting and implementing technological innovations.

As shown in figure 2 below, the TOE framework is categorized into three contexts namely technological factors, organizational factors and environmental factors that may have an influence on the process of technology adoption at the firm level.

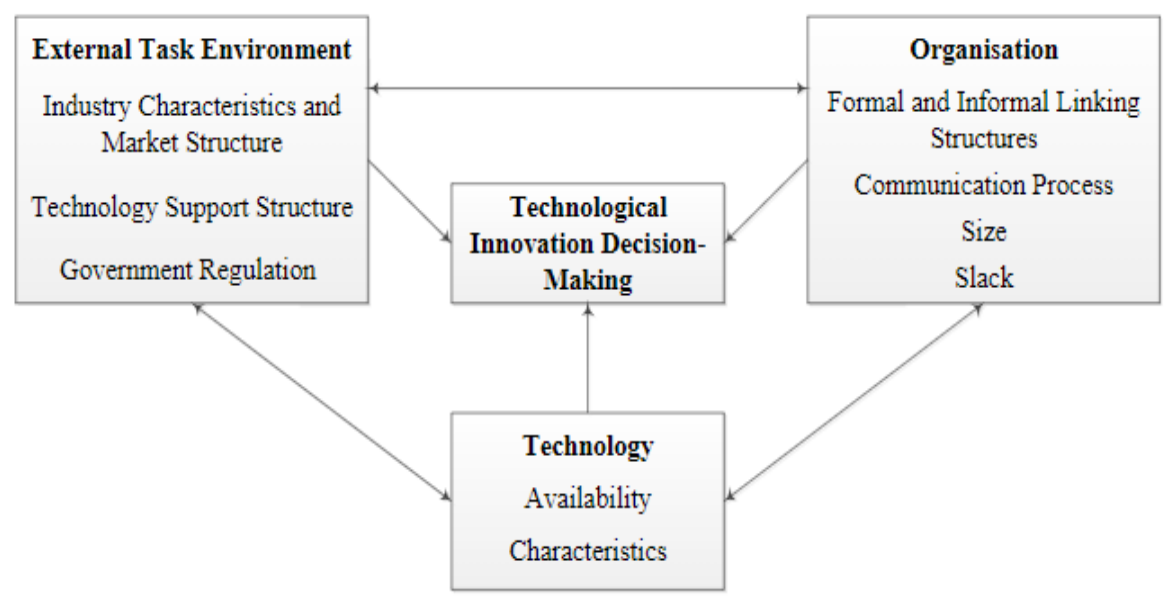


Figure 2: Technology-Organisation-Environment (Tornatzky et al., 1990)

The decision to adopt and use cloud computing will be influenced by technological, organizational and environmental factors.

- Technology factors refer to the existing and new technology that is owned by the company.

- Organisational factors refer to the organizational characteristics such as organization size, organization structure and top management support of the company

- Environmental factors refer to external factors that may influence the adoption of technology such as the regulatory environment, competitive pressure and industry pressure in which the firm operates.

\subsection{Contingency Theory}

The basis of contingency theory is that there is no one best way of organizing and managing an organization. According to [10], contingency theory is defined as a variable that moderates the aspects of organizational characteristics on organizational performance. The contingency theory permits organizational characteristics such as strategies and structure to be aligned with the organisation's objectives to achieve organizational performance.

According to researcher [9], contingency theory has components as shown in figure 3 , such as organizational strategy, organizational structure and organizational performance that would influence the organizational performance [11].

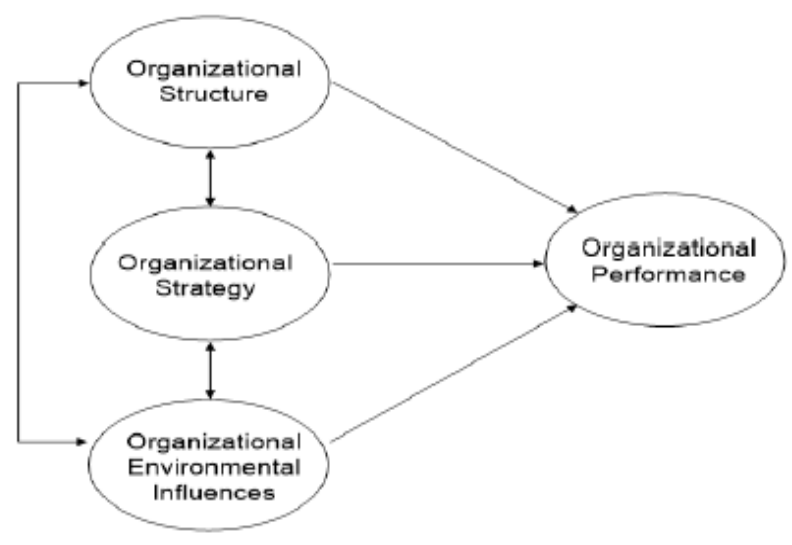

Figure 3: Contingency Theory (Blanton, Watson, and Moody, 1992)

\subsection{Conceptual Framework}

This section discusses how elements of theories underpinning this are presented as a conceptual research framework. The strategic cloud computing framework is constructed (Figure 4) consisting of four constructs. 


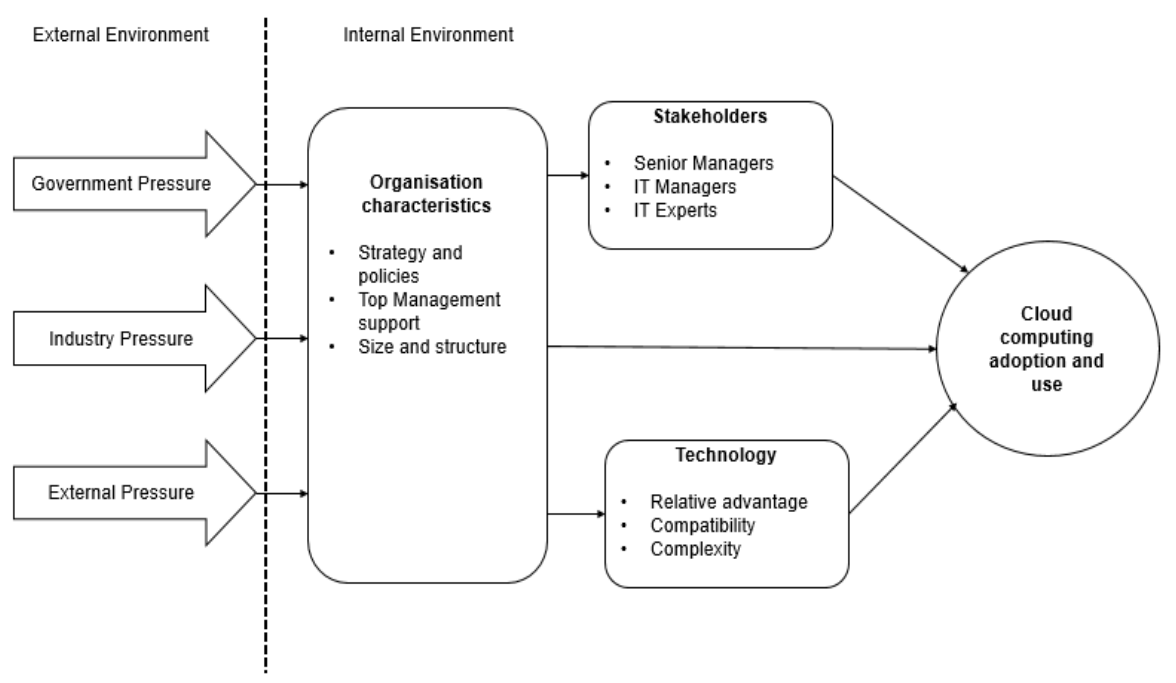

Figure 4: Strategic cloud computing framework (Researcher)

As shown in the figure above, strategic cloud computing is made of the external environment, internal environment, stakeholders, and technology context.

- External environment. - Consists of external factors that may influence the adoption and use of cloud computing. The external environmental constructs include government regulation, competition pressure and industry pressure.

- Internal environment - consists of internal factors namely organizational characteristics that may influence the adoption and use of cloud computing. The internal environment constructs include organisation strategy and policies, top management support, organization size and organization's structure.

- Stakeholders - consists of all stakeholders that may influence the adoption and use of cloud computing. The stakeholder's constructs include stakeholders such as Manager, IT experts and Consultants who have experience and decision making regarding the adoption and use of cloud computing.

\section{Research Methodology and Design}

This section discusses the research methodology and research design for a strategic cloud computing framework in the context of the South African IT professionals.

\subsection{Research Philosophy}

According to [12], research philosophy refers to the set of beliefs concerning the phenomena or the nature of the reality that is being researched. The research philosophy can be positivism, interpretivism, realism, and pragmatism.

This study used interpretivism as the research philosophy, which considers the experiences of individuals as the main source of interpreting reality. Interpretivism researcher believes that reality 
consists of people's subjective experiences of the external world [13]. The interpretivism research philosophy allows the researcher to obtain rich and deep data on cloud computing adoption and use from the individual IT professional context.

\subsection{Research Approach}

A research approach can be categories as a quantitative research approach and qualitative research approach. According to [12], the research approach is defined as a way to treat and analyse the selected data into a quantitative way or qualitative way.

This study used a qualitative research approach to address the research questions. The interpretivism research philosophy goes hand in hand with the qualitative research approach nature of this study.

\subsection{Research Strategy}

The research strategy is defined as a plan on how the research goes about answering the research question [13]. The research strategy can be experimental research, surveys, action research, ethnography, case study, and archival research.

The study used the case study research strategy given the interpretive position and the nature of research questions. According to [14] case study research strategy allows the researcher a deep understanding of a phenomenon. A case study was selected to obtain IT professional's views and experience on the adoption and use of cloud computing.

\subsection{Research Design}

The research design focuses on the outcome and all the steps in the process to achieve the outcome. The research design also considers the type of data that will be collected such as qualitative data.

\subsubsection{Selection setting and research participants}

Both purposive sampling and snowball sampling were suitable for this study. According to [15], purposive sampling focuses on a particular characteristic of a population that of interest. Snowball sampling is based on choosing samples depending on availability or accessibility

The selection criteria included views, experiences and opinion on cloud computing. The study participants included senior managers, managers and IT experts with experience of cloud computing.

\subsubsection{Research Instruments}

This study used interviews and observations to collect data. The two research instruments allowed the collection of rich data about cloud computing to answer the research questions.

- Interviews - researcher conducted semi-structured interviews with individual IT personnel. This was set out to determine how cloud computing could be strategically adopted and use in the context of the South African IT professionals.

- Observations - is a technique that involves watching and recording the behaviour of a living being. The researcher kept observation notes. The observation supported the semi-structured interviews.

\subsection{Data collection}

Data collection is described as the process of gathering and measuring information on the established systematic way and it enables the researcher to answer the research questions. 
The primary data was collected using semi-structured interviews from IT professionals such as managers, professionals, experts, and consultants. Baker and Edwards [16], suggests a sample of between 12 and 60 interviews as the guideline. Drawing from Baker and Edwards, the semi-structured interviews were conducted with a sample of 21 participants.

\subsection{Data Analysis}

Data analysis is described as the process that involves organizing, examining and categorizing data with the aim of deriving meaning to find answers to the research question [15].

Thematic analysis was used to analyse the data [17]. The study used qualitative data to determine how cloud computing could be strategically adopted and use in the context of South African IT professionals.

The semi-structured interview data were transcribed verbatim to interview scripts. The data were organized into patterns of categories and themes. Thematic analysis was used to identify common themes as well as the relationships among them.

\section{Findings and Discussions}

The data collection was conducted using semi-structured interviews. The thematic data analysis approach was used to identify themes from interviews. The four themes, which were used in the data analysis, were derived from the four study objectives stated as follows

- To analyse the landscape of cloud computing through the eyes of IT professionals.

- To analyse the drivers of cloud computing for different stakeholders.

- To analyse and describe practical and theoretical contingencies for cloud computing.

- To analyse and describe factors influencing cloud computing amongst South African information technology professional

\subsection{Theme 1: Cloud computing landscape}

The main objective of theme one is to understand the landscape of cloud computing through the eyes of information technology professionals. The questions asked in this section were designed to assist with the understanding of the concept of cloud computing, the essential things to be taken into consideration when moving workloads into the cloud environment, the benefits of cloud computing over on-premise computing. In addition, the questions were asked to understand the deployment and service model in the context of individual IT professionals.

Participants were asked to define cloud computing according to their own understanding. The extract shared expressed the viewpoint of a participant. "Cloud computing is simply an external data centre that you can connect via the internet to be able to create a virtual machine or leverage on existing software." (Participant 03). From the responses, it can be deduced that most of the participants managed to identify cloud computing as consuming IT resources via the internet. The definitions provided by participants concur with the literature of [18], where researchers from that study, defined cloud computing as a collection of hardware and software that runs in a data centre and enable computing model.

Participants recognized the importance of cloud computing and the benefits that come with cloud computing. The extracts in response to the benefits of cloud computing over on-premise computing. One participant elaborated that "Cloud computing gives you the competitive advantage...cloud computing provides us with enterprise technology." (Participant 10). Another extract "Cloud computing 
services allow testing of new products, allows flexibility since staff members can be able to access corporate data at any time regardless of their locations." (Participant 11). The literature reveals that cloud computing benefits include the following, pay as you use model, scalability, flexibility, competitive advantage, innovation and costs savings [19].

Participants were asked questions about different deployment and service models that are most appropriate in the context of their work. Participants perceived that most commonly used cloud computing applications are Microsoft One Drive, Microsoft Teams, Microsoft Office365, Google Gmail, and DropBox. The findings concur with the findings of a study by Erdogmus [20]. The study found that Software as a service is considered to be the main concept behind cloud computing regardless of deployment model.

\subsection{Theme 2: Cloud computing stakeholder value}

The main objective of theme two was to understand what value cloud computing brings to different stakeholders. The questions asked in this section were designed to analyse the stakeholder influence on cloud computing use and adoption. In addition, how does each stakeholder derive value from using cloud computing and what influence do different stakeholders have on what happens in the organization.

The following extract provides perceptive regarding stakeholders "...you can't go ahead and implement cloud services without the buy-in of stakeholders". (Participant 10). The findings from this theme are that there is a need to manage stakeholders. The relationship between stakeholders and the organization needs to be understood. In addition, the role of stakeholders in the organization decision making is gaining more attention. The literature reveals that stakeholder theory is used to examine managerial decisions about balancing stakeholder interests.

\subsection{Theme 3: Cloud computing contingencies}

The main objective of theme three was to analyse the contingencies that will enable cloud computing adoption and use. The literature reveals that contingency theory indicates the organizational characteristics such as strategy and structure that need to be aligned with the organisation's objectives to achieve organizational performance.

The questions asked in this section were designed to assist with the understanding of the practical and theoretical contingencies for cloud computing. The question was asked, in what is the business or IT strategy influence cloud computing adoption and use. The findings from participants are that the IT strategy needs to be aligned to business strategy for cloud computing to be smoothly adopted and use in an organization.

The extract shared expressed the viewpoint of a participant. "IT Strategy needs to align with technology trends to be able to meet the company's objectives and goals." (Participant 03). In addition, from the responses, it can be deduced that organizational structure does not influence the decision to adopt or to use cloud computing.

Many factors may influence the adoption and use of cloud computing. The findings from the environmental context, the factors such as government policy, legal environment and competition pressure seemed to influence the adoption and use of cloud computing.

\subsection{Theme 4: Cloud computing factors}

The main objective of theme four was to identify factors affecting the adoption and use of cloud computing. Based on the literature review TOE framework was considered to an appropriate theoretical framework to identify factors that influence the adoption and use of cloud computing. The questions 
asked were designed to understand the organizational characteristics and technological competence when adopting or using cloud computing.

The findings point to top management support, relative advantage, data security, complexity and technical competencies as the most important factors that may affect the adoption and use of cloud computing.

The extract shared expressed the viewpoint of a participant."...Security remains a concern as the data is being moved into the cloud computing environment." (Participant 11). Another finding is that the size of an organization is not seen as an important factor when adopting and using cloud services. A small organization is able to compete with big corporate using cloud services. The technological factors that are important include top management support, compatibility with the existing technology.

\section{Conclusion}

The main contribution of the study was to present a strategic cloud computing framework that can be used to help strategically adopt and use cloud computing in a uniformed and coordinated manner in South Africa.

This paper revealed that cloud benefits play a major role in getting an organization to adopt and use cloud computing. It also revealed that the key role of stakeholders, in that stakeholder has an influence on cloud computing use and adoption.

The organisation's strategy and organization structure will determine to what extent cloud computing could be smoothly adopted and use in an organization to reposition itself as a strategic enabler. It further revealed that environmental context, the factors such as government policy, legal environment and competition pressure seemed to influence the adoption and use of cloud computing.

The paper further revealed that top management support, relative advantage, data security, complexity, and technical competencies as the most important factors that might affect the adoption and use of cloud computing in South African.

\section{References}

[1] B. Hayes, "Cloud computing," Commun. ACM, vol. 51, no. 7, p. 9, Jul. 2008.

[2] P. Mell, T. Grance, and T. Grance, "The NIST Definition of Cloud Computing Recommendations of the National Institute of Standards and Technology," Natl. Inst. Stand. Technol. Inf. Technol. Lab., vol. 145, p. 7, 2011.

[3] S. Marston, Z. Li, S. Bandyopadhyay, J. Zhang, and A. Ghalsasi, "Cloud computing - The business perspective," Decis. Support Syst., vol. 51, no. 1, pp. 176-189, 2011.

[4] J. Varia, "Migrating your existing applications to the AWS cloud," A Phase Driven Approach to Cloud Migr., 2010.

[5] V. Chang, R. J. Walters, and G. Wills, "Review of Cloud Computing and Existing Frameworks for Cloud Adoption," IEEE Secur. Priv., no. 2014, p. 35, 2011.

[6] S. K. Nair et al., "Towards secure cloud bursting, brokerage and aggregation," in Proceedings - 8th IEEE European Conference on Web Services, ECOWS 2010, 2010.

[7] R. E. Freeman, Strategic management: A stakeholder approach, vol. 1. 1984.

[8] L. G. Tornatzky, M. Fleischer, and A. K. Chakrabarti, The processes of technological innovation. Lexington Books, 1990.

[9] J. E. Blanton, H. J. Watson, and J. Moody, "Toward a Better Understanding of Information Technology Organization: A Comparative Case Study,” MIS Q., vol. 16, no. 4, p. 531, 1992. 
[10] L. Donaldson, The Contingency Theory of Organizations. Sage Publications, 2001.

[11] N. S. Umanath, "The concept of contingency beyond 'It depends': Illustrations from IS research stream," Inf. Manag., 2003.

[12] A. Bryman and E. Bell, "Business Research Methods," Methods, vol. 3, no. 1, p. 595, 2007.

[13] M. Saunders, P. Lewis, and A. Thornhill, "Research Methods for Business Students," in Research methods for business students, vol. 6th, 2016, p. 649.

[14] R. K. Yin, Qualitative research from start to finish. 2016.

[15] J. Creswell and V. Clark, Designing and conducting mixed-methods research. Thousand Oaks, CA: Sage. 2007.

[16] S. E. Baker and R. Edwards, "How many qualitative interviews is enough ?," Natl. Cent. Res. Methods Rev. Pap., 2012.

[17] V. Braun and V. Clarke, "Using thematic analysis in psychology," Qual. Res. Psychol., 2006.

[18] M. Armbrust et al., "A view of cloud computing," Commun. ACM, vol. 53, no. 4, p. 50, 2010.

[19] M. Miller, Cloud Computing: Web-Based Applications That Change the Way You Work and Collaborate Online. Indianapolis: Que Publishing, 2009.

[20] H. Erdogmus, "Cloud Computing: Does Nirvana Hide behind the Nebula?," IEEE Softw., vol. 26, no. 2, pp. 4-6, Mar. 2009. 